\title{
Changes in biochemical analytes in female dogs with subclinical Ancylostoma spp. infection
}

\author{
Elizabeth M. S. Schmidt', Asta Tvarijonaviciute ${ }^{2}$, Silvia Martinez-Subiela², José J. Cerón ${ }^{2}$ and Peter D. Eckersall ${ }^{3^{*}}$ (D)
}

\begin{abstract}
Background: Ancylostoma spp. is one of the most prevalent canine intestinal nematode infections which usually causes subclinical disease in adult dogs and has zoonotic implications. Therefore, the aim of this study was to explore and evaluate the possible pathophysiological changes that Ancylostoma spp. could produce in female dogs naturally infected but without clinical signs of disease, by screening a wide variety of biochemical markers for potential changes. Samples of feces and blood of 45 dogs were collected and fecal flotation and zinc sulphate centrifugal flotation were performed. The biochemical analytes determined were: the acute-phase proteins C-reactive protein (CRP) and haptoglobin ( $\mathrm{Hp}$ ); the lipid profile (cholesterol, triglycerides, $\mathrm{HDL}, \mathrm{LDL}$ ); the serum iron profile: iron, unsaturated iron binding-capacity (UIBC), and ferritin; the enzyme butyrylcholinesterase (BChe); the pancreatic profile: amylase, lipase, and trypsin-like immunoreactivity (TLI); the oxidative stress markers: total antioxidant capacity (TAC) and paraoxonase -1 (PON-1), along with total protein, albumin, and insulin-like growth factor - 1 (IGF - 1). Ancylostoma spp. eggs were detected in 29/45 dogs (64.4\%). Dogs were divided into two groups according to the results of fecal flotation methods. Group 1: negative fecal floatation $(n=16)$, and Group 2: subclinical infection with the observation of Ancylostoma spp. type eggs/ $x 40$ objective fields $(n=29)$.

Results: Mann-Whitney $U$ test was used to compare the biochemical analyte results between the two groups $(P<0.05)$. Significant increases in CRP $(\mu \mathrm{g} / \mathrm{mL})$ (median): non-infected dogs: 5.5 ; subclinically infected dogs 18.7; $P=0.03, \mathrm{Hp}(\mathrm{g} / \mathrm{L})$ (median): G1: 2.4; G2: 3.3; $P=0.03$, and UIBC ( $\mu \mathrm{g} / \mathrm{dL}$ ) (median): non-infected dogs: 139.4; subclinically infected dogs: $216 ; P=0.0015$, and significantly decreased iron $(\mu \mathrm{g} / \mathrm{dL}$ ) (median): non-infected dogs: 202.5; subclinically infected dogs: $125.7 ; P=0.0041$, IGF-1 ( $\mathrm{ng} / \mathrm{mL}$ ) (median): non-infected dogs: 224; subclinically infected dogs: 123; $P=0.02$, and albumin ( $\mathrm{g} / \mathrm{dL}$ ) (median): non-infected dogs: 2.8; subclinically infected dogs: 2.5; $P=0.04$ concentrations were observed in dogs with subclinical Ancylostoma spp. infection when compared to non-infected dogs.
\end{abstract}

Conclusion: These findings provide an overview of the biochemical effects produced by patent Ancylostoma spp. in naturally infected dogs without any evident clinical signs of disease, which could be considered in differential diagnosis, especially in an endemic area for this parasite.

Keywords: Acute phase proteins, C-reactive protein, Haptoglobin, Hookworm, IGF-1, Iron

\footnotetext{
* Correspondence: David.Eckersall@glasgow.ac.uk

${ }^{3}$ Institute of Biodiversity, Animal Health and Comparative Medicine, College of Medical, Veterinary and Life Sciences, University of Glasgow, Glasgow, UK Full list of author information is available at the end of the article
} 


\section{Background}

The hookworm Ancylostoma caninum, Ancylostoma braziliense, and Ancylostoma ceylanicum are among the most prevalent canine helminths. Infection is potentially fatal in young dogs and subclinical in adult dogs. It has zoonotic potential [1, 2], as A. braziliense, A. caninum, and $A$. ceylanicum are etiologic agents of human cutaneous larva migrans, eosinophilic enterititis, anemia, and diarrhea [2-5].

In Brazil, the genus Ancylostoma is the most frequently detected nematode infection in adult dogs and A. caninum is spread throughout the country, presenting serious public health implications due to its zoonotic potential $[6,7]$. Dog feces, shed in crowded cities, contaminate the environment with parasite eggs and larvae, thereby contributing to zoonotic transmission. In southern regions of Brazil, São Paulo and Curitiba, high soil Ancylostoma spp. contamination has been recorded (46.8 \% and $40.3 \%$, respectively) [8-10].

Ancylostoma spp. infects the host mainly through skin penetration or by the ingestion of the third larvae stage which directly reaches the small intestine [11]. In dogs Ancylostoma spp. infection typically results in diarrhea, blood loss and anemia, poor weight gain, dehydration and can affect dogs at any age $[12,13]$. When adult dogs are infected, some larvae invade different body tissues, such as the gastrointestinal tract and skeletal muscles and enter an arrested development phase, resilient to most chemotherapeutic agents. In bitches they can be reactivated during estrus and in the terminal 2 to 3 weeks of pregnancy. They may then be passed via the milk to the litter, for at least one week after parturition $[1,10,11,14]$. Fourthstage larvae and adult worms burrow deeply and massively into the small intestinal mucosa. The parasites are active blood-feeders when attached, by the teeth in their globular buccal capsules, at the intestinal mucosa and thus symptoms might be severe and life threatening especially in puppies in which the peracute and acute disease and blood loss is potentially fatal $[5,11]$. Intestinal infection may occur in female adult dogs and due to age-associated immunity the parasite usually causes subclinical infection in these cases, with eggs shedding in feces but without clinical signs $[12,13]$.

We hypothesized that adult dogs infected with Ancylostoma spp. but without clinical signs could have pathophysiological changes involving inflammation, protein, lipid and iron metabolism, pancreatic function, and oxidative stress. Therefore, the aim of this study was to explore and evaluate the possible pathophysiological changes that Ancylostoma spp. could produce in female dogs naturally infected but without clinical signs. For this purposes a wide variety of biochemical markers were screened for potential changes, including the concentrations of selected acute phase proteins (APPs) to evaluate inflammation such as C-reactive protein (CRP), haptoglobin (Hp), IGF-1, and albumin; a profile to evaluate lipid metabolism [cholesterol, triglycerides, HDL, LDL, and butyrylcholinesterase (BChe)], a profile to evaluate iron metabolism [iron $(\mathrm{Fe})$, unsaturated iron bindingcapacity (UIBC), and ferritin], a pancreatic profile: amylase, lipase, and trypsin-like immunoreactivity (TLI); and oxidative stress markers such as total antioxidant capacity (TAC) and paraoxonase -1 (PON-1).

\section{Results}

Ancylostoma spp. eggs were detected in 29/45 dogs $(64.4 \%)$. Dogs of the both groups were apparently healthy at clinical examination, not showing clinical signs of cachexia, weight loss or diarrhea.

Biochemistry analytes in healthy and infected dogs are presented in Table 1 . Statistically significantly $(P<0.05)$ higher concentrations of CRP (3.2 fold), Hp (1.4 fold) and UIBC (1.5 fold) were observed in infected dogs when comparing with non-infected dogs. In contrast, significantly $(P<0.05)$ lower levels of iron $(1.4$ fold $)$, IGF-1 (1.6 fold) and albumin (1.1 fold) were observed in infected dogs when compared to non-infected dogs. Fold values represent fold differences between the median values of each group.

Significant differences between Ancylostoma spp. subclinically infected and non-infected dogs were not observed for other analytes (Table 1).

\section{Discussion}

The main changes observed in female dogs with active shedding of Ancylostoma spp. eggs were increases in serum CRP and Hp, UIBC and decreases in iron and IGF-1. Although male dogs also become subclinically infected, only females dogs were chosen for investigation because they are directly involved in contaminating puppies due to the arrested development of Ancylostoma spp. larvae. Furthermore the current neutering program at São Paulo State University - Veterinary Teaching Hospital, campus of Botucatu, Brazil, is specific for female dogs, which includes controlling the dog population and parasitological diseases and thus enabled sample collection.

$\mathrm{C}$-reactive protein is a major acute phase protein and a sensitive marker of inflammation in dogs and has been used as a biomarker of infectious diseases [15-18]. Haptoglobin is a moderate APP in dogs $[16,19]$. The results obtained in our study could indicate a mild inflammatory response that could be associated with the blood-feeding adult stage of the parasite [11], since the CRP median values of subclinically infected dogs were above our reference range (Table 1) $(>12 \mu \mathrm{g} / \mathrm{mL})$ but lower than the major magnitude increase (10 to 100 fold) stimulated by an acute inflammatory response [16]. 
Table 1 Results of the comparison of CRP, Haptoglobin, and biochemical analytes between dogs non-infected and dogs subclinically infected with Ancylostoma spp.

\begin{tabular}{|c|c|c|c|c|c|}
\hline Analytes & $\begin{array}{l}\text { Non infected } \\
\text { Median [range] }\end{array}$ & $\begin{array}{l}\text { Subclinically infected } \\
\text { Median [range] }\end{array}$ & U value & $P$ value & Reference range \\
\hline$\overline{\operatorname{CRP}(\mu \mathrm{g} / \mathrm{mL})^{\mathrm{a}}}$ & $5.5[5.0-8.7]$ & $18.7[5.0-82.7]$ & 142 & 0.03 & $<12$ \\
\hline Haptoglobin $(\mathrm{g} / \mathrm{L})^{\mathrm{ab}}$ & $2.4[1.1-3.7]$ & $3.3[1.4-5.5]$ & 66 & 0.03 & $<3$ \\
\hline IGF-1 (ng/mL) & $224[63-541]$ & $123[6-123]$ & 66 & 0.02 & $50-400$ \\
\hline $\mathrm{TLI}(\mu \mathrm{g} / \mathrm{L})$ & 9.9 [2.6-14.3] & $7.8[2.1-36.8]$ & 66 & 0.59 & $5.4-32$ \\
\hline $\operatorname{Iron}(\mu \mathrm{g} / \mathrm{dL})^{\mathrm{ab}}$ & $202.5[99.5-437.4]$ & 125.7 [13.0-443.0] & 113 & 0.0041 & $81-220$ \\
\hline $\operatorname{UIBC}(\mu \mathrm{g} / \mathrm{dL})^{\mathrm{a}}$ & 139.4 [18.8-268.5] & $216[5-332]$ & 97.5 & 0.0015 & $130-300$ \\
\hline Ferritin $(\mu \mathrm{g} / \mathrm{L})$ & 107.3 [15.6-197.2] & $121.3[45.1-721.4]$ & 205.5 & 0.53 & 60-190 \\
\hline BChe $(\mathrm{mmol} / \mathrm{mL})$ & $2.6[1.6-4.5]$ & $2.5[0.4-5.0]$ & 201 & 0.46 & $3-5$ \\
\hline PON-1 (UI/mL) & $1.1[0.6-3.6]$ & $1.0[0.5-2.3]$ & 191 & 0.76 & $3.0-4.3$ \\
\hline TAC $(\mathrm{mmol} / \mathrm{L})$ & $0.4[0.08-0.6]$ & $0.5[0.03-0.6]$ & 146 & 0.24 & $>0.35$ \\
\hline Cholesterol (mg/dL) & 142.5 [115.0-311.0] & 125.6 [68.8-293.8] & 194 & 0.37 & $120-300$ \\
\hline $\mathrm{HDL}(\mathrm{mg} / \mathrm{dL})$ & $45.0[7.7-159.3]$ & $43.0[8.7-123.1]$ & 228 & 0.93 & c \\
\hline LDL (mg/dL) & $88.6[71.3-162.6]$ & 92.4 [50.5-171.9] & 201.5 & 0.47 & c \\
\hline Triglycerides (mg/dL) & 56.8 [32.5-88.3] & 51.7 [27.7-119.9] & 222 & 0.82 & $30-200$ \\
\hline Total protein (g/dL) & $6.3[4.5-10.5]$ & $6.5[4.8-9.0]$ & 199.5 & 0.44 & $5.4-7.7$ \\
\hline Albumin $(\mathrm{g} / \mathrm{dL})^{\mathrm{a}}$ & $2.8[1.9-3.2]$ & $2.5[1.8-3.6]$ & 150 & 0.04 & $2.5-3.6$ \\
\hline Amylase (UI/L) & $456.2[252.5-896.7]$ & 570.8 [168.9-1004.0] & 149.5 & 0.56 & c \\
\hline Lipase (UI/L) & $5.1[0.9-14.6]$ & 8.0 [1.1-17.6] & 149.5 & 0.49 & $5.0-200$ \\
\hline
\end{tabular}

Mann-Whitney $U$ tests. $P$ values less than 0.05 are considered statistically significant

${ }^{a}$ Significant difference between infected $(n=29)$ and non-infected dogs $(n=16)$

${ }^{\mathrm{b}} n=28$

${ }^{\mathrm{c} N o t}$ available

The low iron and higher UIBC could reflect a situation of functional iron deficiency being compensated for by the mobilization of iron stores producing a higher transportation capacity of iron and thus increases in UIBC [20]. The decrease in iron could be due to inflammation associated with the damage caused by the worms while attached at the small intestine mucosa [21, 22]. It may also be due to its active blood feeding from lacerated capillaries with subsequently lysis of erythrocytes by pore formation and hemoglobin release into the lumen of the parasite's intestine, resulting in loss of serum proteins, intestinal inflammation and hemorrhage [22, 23]. Ferritin concentrations did not change significantly in our study probably reflecting a mixed effect of increase due to inflammation and decrease due to the mobilization of iron stores to compensate the iron losses [24]. In vivo studies $[23,25]$ suggested that host iron status mediates Ancylostoma spp. pathogenesis, in either parasite development or host susceptibility to infection. Apparently, Ancylostoma spp. infection modulates iron metabolism resulting in enhanced absorption from the intestine to compensate parasite associated-blood loss, but it seems that in our study this increased absorption was not enough to avoid a decrease in serum iron in infected dogs [24, 25].
We did not find low hematocrits or changes in mean cell volume or any other sign of iron deficiency in these dogs in CBCs, but the CBCs in our study were made with an impedance counter and reticulocytes indexes were not analyzed. It could be that in infected dogs, despite the lack of changes in CBCs, reticulocyte indexes could reflect changes both related with the situation of iron loss [26] or inflammation [27]. Although ideally reticulocyte counts and indices should have been investigated, these analytes are not typically determined in non-anemic dogs.

The observed decrease in IGF-1 could be due to a variety of causes, one of these could be the inflammation. Insulin-like growth factor -1 is a negative acute phase protein as its concentrations decreases due to its inhibitory effect of proinflammatory cytokines on the IGF-1 expression in the liver [28]. Moreover, serum IGF-1 concentration decrease in long-term dietary restriction and reduced body size in dogs, and it could be that hookworms can reduce intestinal absorption and produce a decrease in body weight, therefore could also reduce serum concentrations of IGF-1 $[29,30]$.

It is known that in Ancylostoma spp. infection, there can be changes in serum analytes in animals with clinical 
signs of disease; however, in our study, the dogs did not show clinical signs of parasitism. The changes found in this study could provide an overview of the biochemical effects produced by Ancylostoma spp. subclinical infection, which should be considered in differential diagnosis, especially because it is a parasite with zoonotic potential.

No changes were observed in amylase, lipase, and TLI or on the markers related with lipid metabolism (cholesterol, HLD, LDL, butyrylcholinesterase) of the adult female dogs evaluated in this study. This indicates that the subclinical form of infection with this parasite does not affect the pancreas or lipid metabolism. In addition the lack of changes in PON1 and TAC would indicate the absence of an evident oxidative stress in this condition. Although fecal flotation is the most common diagnostic tool in routine examinations and the standard methods were used in this study [31], the major limitations of this study were that a negative result does not mean the dog had had no previous infections with Ancylostoma spp., and the anthelmintic administration previous history was not available.

\section{Conclusions}

Changes in markers of inflammation and iron metabolism were detected in subclinically infected dogs with Ancylostoma spp. parasites. This study contributes towards an understanding of the host-parasite interaction and to improve the knowledge about the pathology associated with this parasite infection. In addition, Ancylostoma spp. infection should be considered in differential diagnosis in apparently healthy dogs showing these changes in APPs and iron metabolism, especially in areas where this parasite is endemic.

\section{Methods}

\section{Animals}

The study population comprised of 45 client-owned adult female mixed breed dogs ( 1 to 3 years old; 10 to $20 \mathrm{Kg}$ ), mean body condition score of 3, admitted to the São Paulo State University Veterinary Teaching Hospital of the Faculty of Veterinary Medicine and Animal Science (FVMZ) for elective ovariohysterectomy in the Population Control Program of São Paulo State University - Faculty of Veterinary Medicine and Animal Science. Inclusion criteria included the availability of complete clinical records as part of the routine care and ultrasound evaluation discarding pregnancy. The stage of oestrus cycle was not determined. The dogs included in the study showed no abnormal findings on physical and clinical examination such as cachexia, weight loss or diarrhea, no anemia or leukocytosis or any other considerable change in hemograms. Only serum remaining after other relevant analyses of importance for diagnostic work-up was used in the present study, and this approach was approved by the Faculty's Animal Experimentation Ethics Committee of the São Paulo State University - FMVZ, UNESP, campus Botucatu (protocol number 245/2011-CEUA).

\section{Laboratory testing \\ Fecal testing}

Fecal samples were collected rectally from each dog and underwent floatation [32, 33] using sodium chloride saturated solution and zinc sulphate centrifugal flotation $[33,34]$. Fecal eggs determination was done on the same day of sample collection to avoid temperature interference as the samples were not refrigerated or frozen. Both methods were performed on all samples and the results were in agreement [31]. Ancylostoma spp. eggs were 55 to $75 \mu \mathrm{m}$ by 34 to $47 \mu \mathrm{m}$ [31]. The dogs were divided into 2 groups. Group 1: with negative fecal flotation (no infection). Group 2: with the observation of fecal Ancylostoma spp. type eggs/x 40 objective fields (subclinical infection). Group 1 included 16 dogs and group 2 included 29 dogs.

\section{Blood analysis}

Blood samples were obtained by jugular vein puncture pre-operatively in tubes with EDTA (BD Vacutainer ${ }^{\circ} \mathrm{K} 2$ EDTA Blood Collection Tube; Becton, Dickinson and Company, USA), to perform the hemogram for every animal. Aliquots of the samples $(3 \mathrm{~mL})$ were also placed in plain tubes with gel separators (BD Vacutainer Blood Collection Tube; Becton, Dickinson and Company, USA) were allowed to clot at room temperature, centrifuged $(1,500 \times \mathrm{g}$ for $5 \mathrm{~min})$ and the harvest sera were stored in Eppendorf microtubes, stored at $-20{ }^{\circ} \mathrm{C}$ with biochemical analyses performed within six months.

Hemograms A full blood count was performed in every animal using an automated Hematology Analyser (Ebram 18 Hemascreen $^{\circ}$ ). There was no anemia or leukocytosis or any considerable change in hemograms.

Biochemistry analysis C-reactive protein (CRP) concentration was measured using a human immunoturbidimetric assay (CRP OSR 6147 Olympus Life and Material Science Europe GmbH, Lismeehan, O'Callaghan's Mills, Co., Clare, Ireland), previously used in dogs [35]. Serum haptoglobin (Hp) concentrations were measured via hemoglobin binding assay previously validated for use in dogs [36]. The concentration of IGF-1 and TLI in the serum samples were analyzed by an automated, solid-phase, enzyme-labeled chemiluminescent, immunometric assay (Immulite IGF-1 and TLI assays; Diagnostic Products, Los Angeles, CA, USA) previously used and described in dogs $[37,38]$.

Serum iron (Iron OSR6186, Beckman Coulter), UIBC (UIBC OSR6124, Beckman Coulter) and ferritin (Tina-quant Ferritin Gen.4, Roche Diagnostic GmbH) concentrations were determined via quantitative assays previously validated [39]. 
Serum BChE activity was measured using a previously reported method [24] using butyrylthiocholine iodide as substrate and adapted for an automated analyser. By this way the activity of $\mathrm{BChE}$, which represents the total amount of $\mathrm{ChE}$ in dog serum, could be quantified [40].

Serum PON-1 was determined with a method previously validated for dogs [41] using p-nitrophenyl acetate as substrate and TAC was measured using a colorimetric method [42].

Total serum HLD, LDL, cholesterol, triglycerides, total protein, albumin, amylase, and lipase were measured using Olympus commercial kits [43, 44].

All assays were measured on an automated biochemistry analyzer (Olympus 600 automatic chemistry analyzer; Olympus Europe GmbH, Hamburg, Germany), with the exception of IGF-1 and TLI that were measured in a chemiluminescent analyser (Immulite, Diagnostic Products, Los Angeles, CA, USA). The biochemical determinations were carried out at the Interdisciplinary Laboratory of Clinical Pathology, INTERLAB - UMU, University of Murcia, Spain.

All assays showed a within run imprecision of less than $10 \%$

\section{Statistical analysis}

All statistics were performed using statistical software (GraphPad Version 6 for Windows, GraphPad Software Inc., San Diego, CA, USA). Data are reported as median and range. All variables were first assessed for normality using the Shapiro-Wilk test. Mann-Whitney $U$ test was used as all of the data were not normally distributed. Statistical significance was set at $P<0.05$ for all analyses.

\section{Acknowledgments}

The authors are grateful to Mary Waterston (University of Glasgow) for the help with part of the laboratory analyses, to Gisele Junqueira dos Santos, and Dr. Alfredo Feio da Maia Lima for helping in sample collection.

\section{Funding}

Part of the present work was carried out at the Institute of Biodiversity, Animal Health and Comparative Medicine, College of Medical, Veterinary and Life Sciences, University of Glasgow, UK and supported by Marie Curie (FP07 Nematode Health System) - ITN 2012 - 264639 (EMSS training fellow grant). Part of this work was carried out at the Interdisciplinary Laboratory of Clinical Pathology, Interlab-UMU, Campus of Excellence Mare Nostrum - University of Murcia, Spain and partially supported by CNPq - Brazil (PD 203241/2014-2) (EMSS PD grant). The funders had no role in study design, data collection and analysis, decision to publish, or preparation of the manuscript.

\section{Availability of data and materials}

All data is contained within the manuscript.

\section{Authors' contributions}

EMSS conceived the study; participated in its design, performed the sample collection and analysis, and drafted the main parts of the manuscript. AT and SMS performed the statistical analysis, created the table and drafted the manuscript. JJC participated in the design of the study and drafted the manuscript. PDE participated in the design of the study and approved the final version of the manuscript. All authors read and approved the final manuscript.

\section{Competing interests}

None of the authors of this paper has a financial or personal relationship with other people or organizations that could inappropriately influence or bias the content of the paper.

\section{Consent for publication}

Not applicable.

\section{Ethics approval and consent to participate}

The study was approved by the Faculty's Animal Experimentation Ethics Committee of the São Paulo State University - FMVZ, UNESP, campus of Botucatu, Brazil (protocol number 245/2011-CEUA). Before enrolling a dog into the study an informed consent from its owner was obtained and approved as part of the protocol number (245/2011-CEUA).

\section{Author details}

${ }^{1}$ Department of Veterinary Clinical Sciences, School of Veterinary Medicine and Animal Science, São Paulo State University (FMVZ -UNESP), Campus Botucatu. Distrito de Rubião Jr, s/n. 18.618-000, Botucatu, SP, Brazil. ${ }^{2}$ Interdisciplinary Laboratory of Clinical Pathology, Interlab-UMU, Campus of Excellence Mare Nostrum, University of Murcia, Murcia, Spain. ${ }^{3}$ Institute of Biodiversity, Animal Health and Comparative Medicine, College of Medical, Veterinary and Life Sciences, University of Glasgow, Glasgow, UK.

Received: 30 July 2015 Accepted: 6 September 2016

Published online: 13 September 2016

\section{References}

1. Stoye M. Biology, pathogenicity, diagnosis and control of Ancylostoma caninum. Dstch Tierarztl Wochenschr. 1992;99:315-21.

2. Traub RJ. Ancylostoma ceylanicum, a re-emerging but neglected parasitic zoonosis. Int J Parasitol. 2013:43:1009-15.

3. Prociv P, Croese J. Human eosinophilic enteritis caused by dog hookworm Ancylostoma caninum. Lancet. 1990;335:1299-302.

4. Epe C. Intestinal nematodes: biology and control. Vet Clin North Am Small Anim Pract. 2009:39:1091-107.

5. Bowman DD, Montgomery SP, Zajac AM, Eberhard ML, Kazacos KR. Hookworms of dogs and cats as agents of cutaneous larva migrans. Trends Parasitol. 2010;26:162-7.

6. Labruna MB, Pena HFJ, Souza SLP, Pinter A, Silva JCR, Ragozo AMA, Camargo LMA, Gennari SM. Prevalência de endoparasitas em cães da aera urbana do município de Monte Negro, Rondônia. Arq Inst Biol. 2006:73:183-93.

7. Dantas-Torres F, Otranto D. Dogs, cats, parasites, and humans in Brazil: opening the black box. Parasites \& Vectors. 2014;7:22-47.

8. Marques JP, Guimarães CR, Vilas Boas A, Carnaúba PU, Moraes J. Contamination of public parks and squares from Guarulhos (São Paulo State, Brazil) by Toxocara spp. and Ancylostoma spp. Rev Inst Med Trop Sao Paulo. 2012;54:267-71.

9. Sprenger LK, Green KT, Molento MB. Geohelminth contamination of public areas and epidemiological risk factors in Curitiba, Brazil. Braz J Vet Parasitol. 2014;23:69-73.

10. Traversa D, di Regalbono AF, Di Cesare A, La Torre F, Drake J, Pietrobelli M. Environmental contamination by canine geohelminths. Parasites \& Vectors. 2014;7:67-76

11. Anderson RC. Nematode parasites of vertebrates: their development and transmission. 2nd ed. London: CAB Publishing; 2000.

12. Taylor MA, Coop RL, Wall RL. Veterinary Parasitology. 3rd ed. Wiley-Blackwell: lowa; 2007

13. Mohamed AS, Moore GE, Glickman LT. Prevalence of intestinal nematode parasitism among pet dogs in the United States (2003-2006). JAVMA. 2009:234:631-7.

14. Miller TA. Influence of age and sex on susceptibility of dogs to primary infection with Ancylostoma caninum. J Parasitol. 1965;51:701-4.

15. Silvestrini P, Zoia A, Planellas M, Roura X, Pastor J, Cerón JJ, Caldin M. Iron status and C-reactive protein in canine leishmaniasis. J Small Anim Pract. 2014:55:95-101.

16. Cerón JJ, Eckersall PD, Martínez-Subiela S. Acute phase proteins in dogs and cats: current knowledge and future perspectives. Vet Clin Pathol. 2005;34:85-99. 
17. Mukorera V, Dvir E, van der Merwe LL, Goddard A. Serum C-reactive protein concentration in benign and malignant canine spirocercosis. J Vet Intern Med. 2011;25:963-6.

18. McClure V, van Schoor M, Thompson PN, Kjelgaard-Hansen M, Goddard A. Evaluation of the use of serum C-reactive protein concentration to predict outcome in puppies infected with canine parvovirus. JAVMA. 2013;243:361-6.

19. McGrotty YL, Knottenbelt CM, Ramsey IK, Reid SW, Eckersall PD. Haptoglobin concentrations in a canine hospital population. Vet Rec. 2003;152:562-4.

20. Weiss DJ. Iron and Copper Deficiencies and Disorders of Iron Metabolism. In: Weiss DJ, Wardrop KJ, editors. Schalm's Veterinary Hematology. 6th ed. Ames: Wiley-Blackwell; 2010. p. 167-71.

21. Georgi JR, LeJambre LF, Ractliffe LH. Ancylostoma caninum burden in relationship to erythrocyte loss in dogs. J Parasitol. 1969;55:1205-11.

22. Kalkofen UP. Intestinal trauma resulting from feeding activities of Ancylostoma caninum. Am J Trop Med Hyg. 1974;23:1046-53.

23. Loukas A, Bethony JM, Mendez S, Fujiwara RT, Goud GN, Ranjit N, Zhan B, Jones K, Bottazzi ME, Hotez PJ. Vaccination with recombinant aspartic hemoglobinase reduces parasite load and blood loss after hookworm infection in dogs. PLoS Med. 2005;2:e295.

24. Crompton DW, Whitehead RR. Hookworm infections and human iron metabolism. Parasitology. 1993;107:S137-45.

25. Held MR, Bungiro RD, Harrison LM, Hamza I, Cappello M. Dietary iron content mediates hookworm pathogenesis in vivo. Infect Immun. 2006;74:289-95.

26. Fry MM. Anemia of inflammatory, neoplastic, renal, and endocrine diseases. In: Weiss DJ, Wardrop KJ, editors. Schalm's Veterinary Hematology. 6th ed. Ames: Wiley-Blackwell; 2010. p. 246-50.

27. Meléndez-Lazo A, Tvarijonaviciute A, Cerón JJ, Planellas M, Pastor J. Evaluation of the relationship between selected reticulocyte parameters and inflammation determined by plasma C-reactive protein in dogs. J Comp Pathol. 2015;152:304-12

28. Colson A, Williems B, Thissen JP. Inhibition of TNF-alpha production by pentoxifylline does not prevent endotoxin-induced decrease inserum IGF-1. J Endorinol. 2003;178:101-9.

29. Greer KA, Hughes LM, Masternak MM. Connecting serum IGF-1, body size, and age in the domestic dog. Age (Dordr). 2011;33:475-83.

30. Breese $C R$, Ingram RL, Sonntag WE. Influence of age and long-term dietary restriction on plasma insulin-like growth factor-1 (IGF-1), IGF-1 gene expression, and IGF-1 binding proteins. J Gerontol. 1991;46:B180-7.

31. Dryden MW, Payne PA, Ridley R, Smith V. Comparison of common fecal flotation techniques for the recovery of parasite eggs and oocysts. Vet Ther. 2005;6:15-28.

32. Willis HH. A simple levitation method for the detection of hookworm ova. Med J Aust. 1921:8:375-6.

33. Mandarino-Pereira A, de Souza FS, Lopes CW, Pereira MJ. Prevalence of parasites in soil and dog feces according to diagnostic tests. Vet Parasitol. 2010;170:176-81.

34. Faust EC, D'Antoni JS, Odom V, Miller MJ, Peres C, Sawitz W, Thomen LF, Tobie J, Walkern JH. A critical study of clinical laboratory techinics for the diagnosis of protozoan cysts and helminth eggs in feces. I: preliminary communication. Am J Trop Med Hyg. 1938;18:169-83.

35. Gentilini F, Mancuni D, Dondi F, Ingrá L, Turba ME, Forni M, Bergamini PF. Validation of a human immunoturbidimetric assay for measuring canine C-reactive protein. Glasgow: 15th ECVIM-CA Congress; 2005.

36. Martínez-Subiela S, Cerón JJ. Validation of commercial assays for the determination of haptoglobin, C-reactive protein and serum amyloid $A$ in dogs. Arch Med Vet. 2005;37:61-6.

37. Trivedi S, Marks SL, Kass PH, Luff JA, Keller SM, Johnson EG, Murphy B. Sensitivity and specificity of canine pancreas-specific lipase $(\mathrm{CPL})$ and other markers for pancreatitis in 70 dogs with and without histopathologic evidence of pancreatitis. J Vet Intern Med. 2011;25:1241-7.

38. Tvarijonaviciute A, Tecles F, Carillo JM, Rubio M, Cerón JJ. Serum IGF-1 measurements in dogs: performance characteristics of an automated assay and study of some sources of variation. Can J Vet Res. 2011a;75:312-16.

39. Martinez-Subiela S, Cerón JJ, Strauss-Ayali D, Garcia-Martinez JD, Tecles F, Tvarijonaviciute A, Caldin M, Baneth G. Serum ferritin and paraoxonase-1 in canine leishmaniosis. Comp Immunol Microbiol Infect Dis. 2014;37:23-9.

40. Tecles F, Martinez-Subiela S, Bernal LJ, Ceron JJ. Use of whole blood for spectrophotometric determination of cholinesterase activity in dogs. Vet J. 2000;160:242-9.
41. Tvarijonaviciute A, Tecles F, Caldin M, Tasca S, Cerón J. Validation of spectrophotometric assays for serum paraoxonase type-1 measurement in dogs. Am J Vet Res. 2012a;73:34-41.

42. Erel O. A novel automated direct measurement method for total antioxidant capacity using a new generation, more stable ABTS radical cation. Clin Biochem. 2004;37:277-85.

43. Tvarijonaviciute A, Tecles F, Martínez-Subiela S, Cerón JJ. Effect of weight loss on inflammatory biomarkers in obese dogs. Vet J. 2012b;193:570-2.

44. Tvarijonaviciute A, García-Martínez JD, Caldin M, Martínez-Subiela S, Tecles F, Pastor J, Ceron JJ. Serum paraoxonase 1 (PON1) activity in acute pancreatitis of dogs. J Small Anim Pract. 2015:56:67-71.

\section{Submit your next manuscript to BioMed Central and we will help you at every step:}

- We accept pre-submission inquiries

- Our selector tool helps you to find the most relevant journal

- We provide round the clock customer support

- Convenient online submission

- Thorough peer review

- Inclusion in PubMed and all major indexing services

- Maximum visibility for your research

Submit your manuscript at www.biomedcentral.com/submit 